\title{
Fluorescence Coupled with Macro and Microscopic Examinations of Morphological Phenotype Give Key Characteristics for Identification of Crude Drugs Derived from Scorpions
}

\author{
Hiroko Tokumoto, ${ }^{a, b}$ Hiroko Shimomura, ${ }^{a}$ Takashi Hakamatsuka, ${ }^{a}$ Yoshihiro Ozeki, ${ }^{c}$ and \\ Yukihiro Goda*,d \\ ${ }^{a}$ Division of Pharmacognosy, Phytochemistry, and Narcotics, National Institute of Health Sciences; 3-25-26 \\ Tonomachi, Kawasaki-ku, Kawasaki 210-9501, Japan: ${ }^{b}$ Graduate School of Engineering, Tokyo University \\ of Agriculture and Technology; 2-24-16 Naka-cho, Koganei, Tokyo 184-8588, Japan: ${ }^{c}$ Department of \\ Biotechnology and Life Science, Faculty of Engineering, Tokyo University of Agriculture and Technology; 2-24-16 \\ Naka-cho, Koganei, Tokyo 184-8588, Japan: and ${ }^{d}$ Division of Drugs, National Institute of Health Sciences; 3-25-26 \\ Tonomachi, Kawasaki-ku, Kawasaki 210-9501, Japan.
}

Received October 4, 2017; accepted January 8, 2018

Microscopic examination of crude drug components has been the traditional method to identify the origin of biological materials. For the identification of components in a given mixture via microscopy, standard reference photographs of fragments derived from different organs and tissues of individual species are required. In addition to these reference photographs, a highly observant eye is needed to compare the morphological characteristics observed under the microscope with those of the references and to then identify the origin of the materials. Therefore, if other indexes are available to be coupled with microscope examination, the accuracy of identification would be significantly improved. Here, we prepared standard reference photographs for microscopic examination to identify powdered and fragmented materials in the crude drug "Quanxie" derived from individual organs of dried scorpion (Buthus martensii KARSCH). Since a remarkable characteristic of scorpion bodies is that they fluoresce under UV light, two methods to identify "Quanxie" were established, including fluorescence fingerprint analysis and microscopic fluorescent luminance imaging analysis. In the former, at least $0.1 \mathrm{~g}$ of powered materials was used, which could be recovered after the measurement, and in the latter, only small amounts of powders were used for microscopic examinations. Both methods could distinguish powders of "Quanxie" from those of other micro-morphologically similar crude drugs, namely, "Chantui," "Sangpiaoxiao," and "Jiangcan." The combination of these methods should improve the swiftness and accuracy of "Quanxie" identification.

Key words Buthus martensii; fluorescence fingerprint; microscopic morphology; microscopic fluorescent luminance imaging analysis; powdered preparation; Quanxie

The origin of crude drugs should be clearly identified to ensure their effectiveness as suitable medicines. Currently, in order to ensure the efficacy of medicines, active components in crude drugs are extracted followed by their identification and quantification by chromatographic techniques such as TLC, HPLC, and gas chromatography coupled with MS., ${ }^{1,2}$ Recent progress in molecular biology has allowed for the use of DNA profiling to extract DNA from dried and powdered crude drugs followed by PCR amplification to obtain nucleotide sequences, and real-time PCR technologies such as TaqMan and SYBR green have allowed for the possibility of species-specific quantification in mixtures prepared from many biological sources. ${ }^{3,4)}$ Although the recent progress in chromatographic and PCR micro analysis has provided us with the means to identify the origin of biological materials in trace amounts, these methods are tedious, expensive, and time-consuming. Compared to these instrumental analytical methods, traditional microscopic examination has economic advantages for the identification of ingredients in cut and powdered crude drugs, ${ }^{5-7)}$ because only a microscope is required. Particularly, fine-powdered materials, which do not need slicing into sections with a microtome, are needed to be placed on slides, fixed with mounting reagents, stained if necessary, and covered with a coverslip, before being placed under a micro- scope for identification. This makes microscopic examination significantly less expensive than instrumental methods, as well as convenient, in situ, and instantaneous. The major difficulty of microscopic examination is the requirement of highproficiency microscopic observation and the prerequisite of detailed and accurate comparative standard reference photographs. Other indices or profiles coupled with microscopic examination are expected to significantly improve the accuracy in crude drug identification over the sole use of microscopes.

The crude drug “Quanxie” (Scorpion, 全蝎) is made from dried whole Buthus martensii KARSCH (Buthidae, Scorpions, Arachnida, Arthropoda) ${ }^{8)}$ and has been used in China as an antispasmodic in pediatric epilepsy, an analgesic for headache and joint aches, and to treat stroke, bronchitis, and parotitis. ${ }^{9-11) ~ " Q u a n x i e " ~ i s ~ o n e ~ o f ~ t h e ~ c r u d e ~ d r u g s ~ i n ~ " U s a i e n, " ~ t h e ~}$ ancient crude drug formulation described in "Korean Wazaikyokuho (Taioing Huimin Heji Jufang Zochuhon version)",12) as being one of the valuable possessions found in the Kunozan Toshogu shrine, Japan. Microscopic examination of a trace amount of the dry black preparation remaining at the bottom of the gallipot for Ieyasu Tokugawa, the first shogun of the Edo shogunate in Japan approximately 400 years ago revealed that the medicine contained in the gallipot was "Usaien."13)

Buthidae belongs to the largest family of scorpions; in 
total, 1101 species in 90 families have been identified worldwide. ${ }^{14)}$ Studies on scorpions for taxonomical purposes were conducted long ago and were focused on external macromorphological features. ${ }^{14-16)}$ These did not include any studies on B. martensii. The studies on Buthidae by Pavlovsky ${ }^{17-19)}$ provided useful morphological information regarding each organ system, such as gastrointestinal organs and respiratory organs, from an anatomical viewpoint, but no description of B. martensii, specifically, was included.

Scorpion research has been conducted in Japan for many years and Takashima ${ }^{20-22)}$ and Isshiki and Yonezawa ${ }^{23)}$ have both described B. martensii. They reported that B. martensii lacks a subaculear tubercle beneath the aculeus, that the number of teeth on the pectene ranges from 16 to 25 , and that it has tibial spur at the top of the tibia of the third and fourth legs. These characteristics differentiate it from the other Japanese domestic scorpions, Isometrus europaeus and Liocheles australasiae.

In the pharmacognosy field, the identification of the dried and powdered scorpion as a crude drug using morphological features, especially with microscopic observation, has rarely been reported other than by $\mathrm{Xu}^{24)}$ and Zhang et al. ${ }^{25,26)}$ Animal-based crude drugs, especially those derived from insects, are complex and diversified compared to plant-based crude drugs. Many plant-based crude drugs are prepared from specific and limited organs and tissues, such as leaves, stems, roots, and seeds in which the medicinal components are accumulated. The powdered contents of these drugs become homogenous fragmented tissues and organs that can be identified easily with a microscope. In crude drugs derived from insects such as scorpions, the whole body including whole organs and tissues are crushed and fragmented. The resultant powder includes a complex mixture of tissues and organs, which constitute one drug, making it difficult to identify its origin. Confusion in the identification of scorpion has also been caused by inaccurate identification of the origins of the Buthidae species and by the inconsistent nomenclature of tissues and organs in the literature. For example, some literature concerning scorpions have reported seven segments in the prosoma, ${ }^{9,27)}$ but other sources have reported six segments, ${ }^{27,28)}$ and nomenclatures of the legs vary with the author. ${ }^{27-30)}$ In order to give an accurate name to the tissue fragments observed in powdered crude drugs, it is a pre-requisite to possess true and correct original materials along with correct names for fragmented and powdered tissues and organs found in the drug.

In the case of the identification of elements present in powdered "Quanxie," while some characteristics of the muscles and exoskeleton were already indicated in the old literature, ${ }^{10,24)}$ a complete accounting of the characteristics of all individual parts of organs and tissues that make up the whole $B$. martensii body is unavailable. Identification of the characteristics of many $B$. martensii parts such as the book-lung and the pectenes, which are organs specific to the scorpions, remains to be performed. Furthermore, standard reference microphotographs of all $B$. martensii parts including whole tissues and organs still need to be produced.

The accuracy of crude drug identification by microscopic examination would be much greater if it was coupled to other evidence. It has been reported that scorpions fluoresce when illuminated with UV light. ${ }^{31-34)}$ Studies on scorpion fluorescence have revealed that this fluorescence is due to the presence of $\beta$-carbolines (norharman) ${ }^{35)}$ and hymecromone, ${ }^{36}$ ) which are generally thought to be contained in the epicuticle and hyaline layers. ${ }^{37,38)} \beta$-Carbolines, a physiologically active class of molecules, act on the central nervous system to inhibit monoamine oxidase activity and may alter the level of brain neurotransmitters. They exist in natural materials such as baked meat, spices, coffee, and tobacco smoke and recent reports have indicated that they might be mutagenic in humans. ${ }^{39,40)}$ Hymecromone has been chemically synthesized and widely used as a fluorescent marker in enzyme assays and also as a medicine for seizures and biliary tract diseases, and has been detected in cuticle of arthropods. ${ }^{36)}$ Since both $\beta$-carbolines and hymecromone are reported to be naturally contained in the epicuticle and hyaline layers of scorpions, the existence of these compounds in the fragmented tissues and organs being observed should help to improve the identification of "Quanxie."

In this study, first, a detailed observation of mesoscopic morphology was performed in order to identify the correct origins of tissues and organs in commercially available scorpions. Later, powders were prepared from each tissue and organ and observed with a microscope to create standard reference photographs for the identification of fragmented scorpion parts contained in drug preparations. In order to improve identification of the powders, two fluorescence analyses were used. One was the fluorescence fingerprint method $^{41,42)}$ where the fluorescence spectrum was measured after irradiation with a continuous spectrum, while the other was a microscopic fluorescent luminance imaging analysis in which the distribution of luminance at different wavelengths was observed using microscopic fluorescence filters at pin-points in the observation fields and the results were shown as histograms. These two methods coupled with microscopic examination may improve and support the identification of the crude drug powders obtained from scorpions.

\section{MATERIALS AND METHODS}

Materials The crude drug "Quanxie" (Uchida Wakanyaku Ltd., Tokyo, Japan, NIHS-DPP-20010-92-27), preserved in the Division of Pharmacognosy, Phytochemistry and Narcotics, National Institute of Health Sciences, was used as the main observation material. Commercially available, Japanese commercial brand "Quanxie" was gifted by Tochimoto Tenkaido Co., Ltd., Osaka, Japan (Lot 064014001, NIHSDPP-20011), and Takasago Yakugyo Co., Ltd., Osaka, Japan (Lot 022916, NIHS-DPP-20012) (Fig. 1). Vietnam commercial brand "Toàn yết"3)" (NIHS-DPP-20013, NIHS-DPP-20014) was obtained for comparative observation. Other crude drugs derived from insect origins, “Chantui" (Cicada Slough, 蝉退) (Uchida Wakanyaku Ltd., NIHS-DPP-92-06) and "Sangpiaoxiao" (Mantis Egg-case, 桑螵蛸) (Uchida Wakanyaku Ltd., NIHS-DPP-92-52) were preserved in the Division of Pharmacognosy Phytochemistry and Narcotics, National Institute of Health Sciences. Cut “Jiangcan” (Stiff Silkworm, 白殭蚕) was purchased from Daikoshoyaku Co., Ltd., Aichi, Japan (Lot. 6127, NIHS-DPP-20030).

Observation of Morphological and Microscopic Characteristics under Visible Light The surfaces of crude drugs were observed using a digital microscope (VH-8000C; Keyence Co., Osaka, Japan) with a VH-Z25 zoom lens (Keyence) 
and Olympus SZ stereomicroscope (Olympus Co., Tokyo, Japan). Microscopic morphology was observed using normal and polarized light with a $\mathrm{BH}-2$ (Olympus) attached to a $\mathrm{VH}$ 8000C and Axio Scope A1 (Carl Zeiss AG, Oberkochen, Germany). For microphotography, a Micrograph Imager Olympus PM-10AK (Olympus), VH-8000C, and DP-21 digital camera (Olympus) were used.

The fine structure of each material was observed by preparing sectioned specimens. Rough sections of whole "Quanxie" were cut approximately 3 to $5 \mathrm{~mm}$ wide using a razor blade. These sections were then wetted with water for 20 to $30 \mathrm{~min}$ at room temperature until they were swollen, frozen, and sliced 30 to $60 \mu \mathrm{m}$ thick using a freezing microtome (Kelk Ltd., Kanagawa, Japan). The sections were placed on glass slides and mounted with a mixture of glycerol and water $(1: 1)$, as mentioned in the "Microscopic examination" section of the Japanese Pharmacopoeia 17th edition $(\mathrm{JP} 17)^{7)}$ and covered with a coverslip. A surface view was used in order to prepare sequential sections that were parallel at the surface (paradermal sections). Transverse (cross) and longitudinal (vertical) sections were prepared by slicing the body in midline and parallel directions, respectively. For the observation of oils, Sudan III staining was performed according to the literature. $^{44)}$

For the observation of powdered samples, dried whole "Quanxie" or individual organ sections cut using a razor blade were pulverized with a mortar and pestle. Since some "Quanxie" drugs were obtained from the hard scorpion external skeleton or accumulated high amounts of oil, pulverized materials were sieved through a \#50 $(300 \mu \mathrm{m})$ stainless-steel sieve to isolate the particles categorized as "moderately fine powder" to "very fine powder." In accordance with the procedure described in the "Microscopic examination" section of JP17, approximately $1 \mathrm{mg}$ of powder was mixed with a drop of mounting agent on a glass slide using a small glass rod to prevent the formation of air bubbles, and allowed to stand until rehydrated. An additional drop of mounting agent was then added and a coverslip was placed on the slide. Under an optical microscope, pictures of the microscopic characteristics of each sample were taken in order to prepare standard microscopic reference photographs of powdered "Quanxie" for identification.

In this report, tissues and organs are referred to with the names used in previously published books. ${ }^{28,45-50)}$

Fluorescence Fingerprint Analysis Fluorescence of crude drugs was observed after irradiation with UV light at $365 \mathrm{~nm}$ using a ChromaDoc-It Imaging System (Ultra-Violet Products Ltd., Cambridge, U.K.). A fluorescence spectrophotometer (F-7100, Hitachi High-Tech Science Co., Tokyo, Japan) was used. Measurement conditions were as follows: slit width of $5 \mathrm{~nm}$ for both excitation and fluorescence; excitation and fluorescence wavelengths of 200-600 and 200-750 nm, respectively; sampling intervals of 10 and $5 \mathrm{~nm}$ for excitation and fluorescence, respectively; photomultiplier tube voltage of $400 \mathrm{~V}$; scan speed of $60000 \mathrm{~nm} / \mathrm{min}$; response set to the automatic mode. The powders were placed into a solid cell prior to analysis with the spectrophotometer and three-dimensional measurements were taken. Each measurement took approximately $2 \mathrm{~min}$, and three repetitive measurements were taken. Whole of "Chantui," parts of "Chantui" eyes and thorax, and surface layers of "Sangpiaoxiao" and "Jiangcan" were simi- larly treated and the fluorescence fingerprints were measured under the same conditions as above.

Microscopic Fluorescent Luminance Analysis at Pixel Level "Quanxie" and its fine powder, excluding the very fine powder, were observed under an inverted fluorescence phase contrast microscope BZ-X700 (Keyence). The excitation/emission wavelengths and dichroic mirror wavelength of the filters were 4',6-diamidino-2-phenylindole (DAPI): 340-380/435-485, 400 nm, green fluorescent protein (GFP): 450-490/500-550, $495 \mathrm{~nm}$, and tetramethyl-rhodamine (TRITC): 522.5-557.5/570-640, $565 \mathrm{~nm}$, respectively. Data in the range of $0-255$ stepwise gradients for each pixel were monitored with a CCD 8-bit camera and the luminance brightness distribution within the designated region of the tissue fragments was shown as a histogram. "Chantui" powder, surface layers of "Sangpiaoxiao" and "Jiangcan," and a mixture of powdered "Quanxie" and "Chantui" (1:1) were observed in the same manner.

\section{RESULTS}

Morphological Characteristics of Commercially Available "Quanxie" and Other Drugs Derived from Insects Observed under Fluorescent Light "Quanxie" is commercially available as dried whole body and as broken pieces (Figs. 1A-E). A unique characteristic of scorpions is that they emit fluorescence under illumination with UV light (Figs. 1A(2) and E). Such fluorescence could also be observed in parts of the cicada slough "Chantui," mantis egg-case "Sangpiaoxiao," and stiff silkworm "Jiangcan" (Figs. 1F-H). Crushed and powdered "Quanxie" can be difficult to distinguish from crushed and powdered "Chantui," "Sangpiaoxiao," or "Jiangcan." Since parts of all these dried insects fluoresce under UV light illumination, the superficial observation of fluorescence could not be used to distinguish between them. Detailed morphological and fluorescent observations were therefore required to identify "Quanxie" from other insect materials.

Mesoscopic Morphological Characteristics of "Quanxie" as Seen by Microscopic Observation (Fig. 2) The nomenclature of scorpion organs, especially the legs, has been used with contradictory meanings by differing authors, as mentioned before. Here, we adopted the nomenclature of the legs described as the opinion of Couzijn in the literature. ${ }^{30)}$

Prosoma (Figs. 2A-G) As shown in Fig. 2, the carapace (a) is accompanied by one pair of shiny reddish-brown ocelli (median eyes (b)) at the center and three pairs of ocelli (lateral eyes $(c)$ ) on either side. Many reddish-brown tubercular processes $(d)$ are scattered on the surface and concentrated around the eyes. The appendages of the first segment are chelicerae (e) followed by pedipalps and legs. On the ventral-side surface of the prosoma, coxa $(f)$ and coxal endites (gnathobase $(g),{ }^{28)}$ Figs. $2 \mathrm{~B}$ and $\mathrm{C}$ ), which are important tissues in the feeding process, were observed at the bottom of the first two pairs of legs with numerous colorless short hair $(h 1)$. Chelicera (e) are accompanied by dark-reddish teeth (i) and densely brown long hair (h2) (Fig. 2D).

Pedipal chela ( $j$ ) (Fig. 2E), accompanied by a regularlyarranged reddish denticle row $(k)$, brown bristle hair assumed to be seta $(h 3)$, colorless or grayish-white short hair $(h 4)$, and long brown hair assumed to be trichobothrium $(h 5),{ }^{29,51)}$ were observed. 


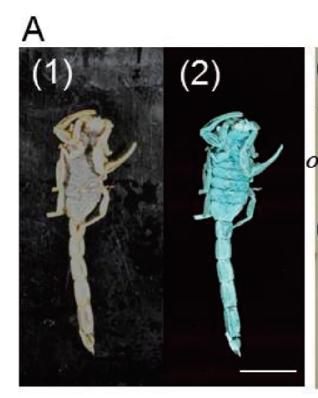

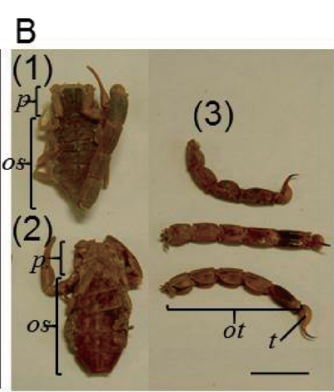

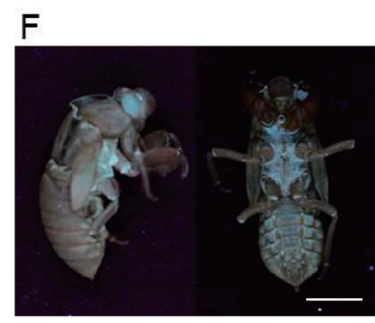

C

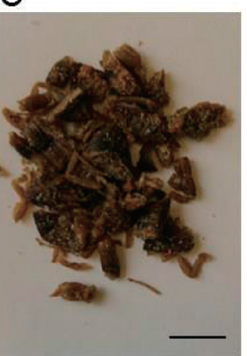

G

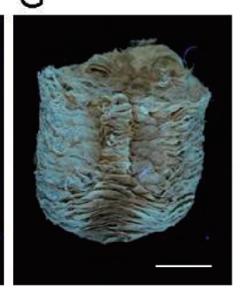

D

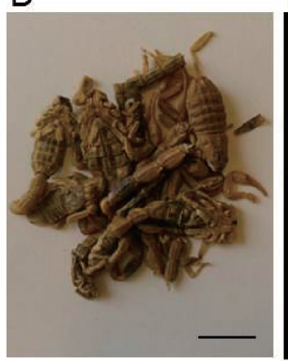

$\mathrm{H}$
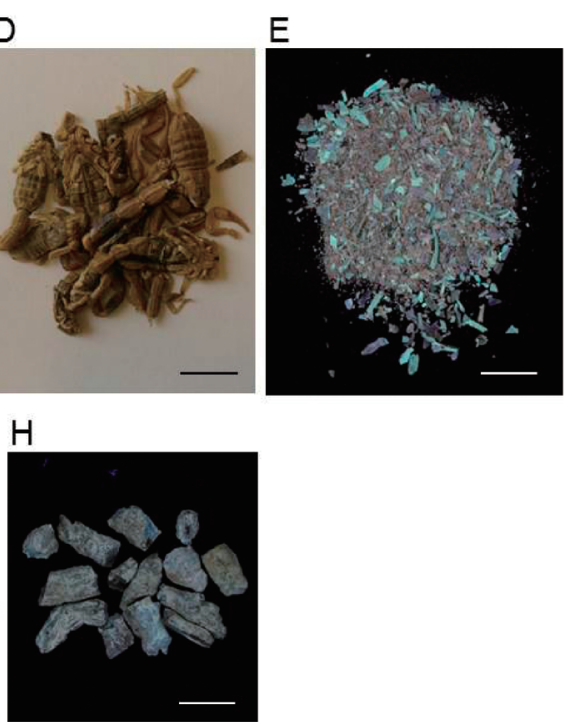

Fig. 1. Photographs of Commercial Crude Drug Derived from Scorpions (A-E) or from Insects (F, G) Observed under Visual and UV Light

"Toàn yết" acquired from Vietnam (A) photographed under visual light (1) and UV light at $365 \mathrm{~nm}$ (2). "Quanxie" from Uchida Wakanyaku Ltd. (B): ventral side (1) and dorsal side (2) metasoma and telson (3). Cut "Quanxie" from Tochimoto Tenkaido Co., Ltd. (C). "Quanxie" from Takasago Yakugyo Co., Ltd. (D). Coarse "Quanxie" powder from Uchida Wakanyaku Ltd. (E), "Chantui" (F), "Sangpiaoxiao" (G) and cut "Jiangcan" (H) photographed under UV light at $365 \mathrm{~nm}$. Bar length: $1 \mathrm{~cm} . p$ : prosoma, os: mesosoma, ot: metasoma, $t$ : telson.
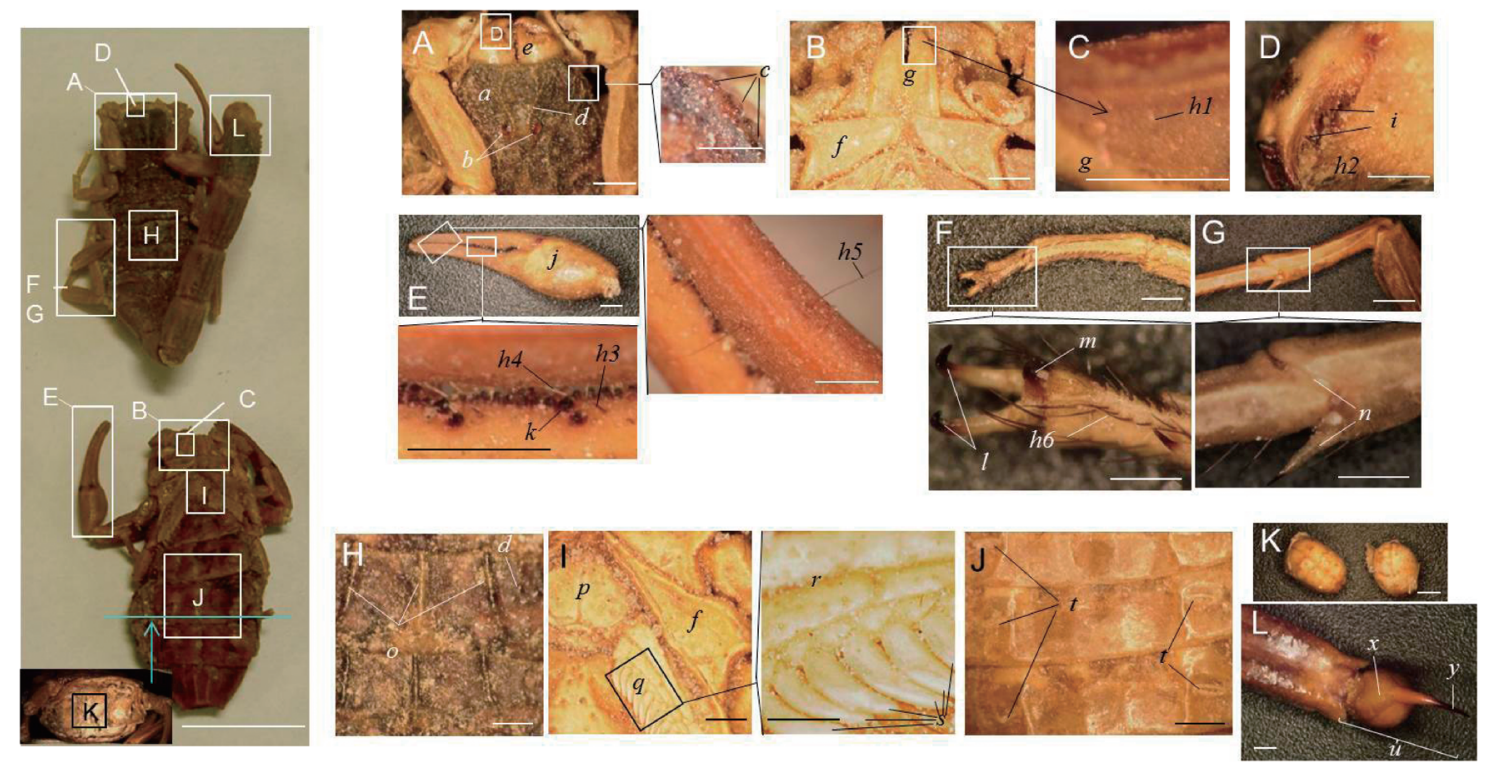

Fig. 2. Photographs of "Quanxie" Morphological Characteristics

The left panel shows the macro-morphology of the "Quanxie" body with particular areas notes by the letters (A) to (L). Bar length: $1 \mathrm{~cm}$. Dorsal side of the prosoma (A)-the right hand photograph shows an enlarged observation of the squared area; Ventral side of the prosoma (B); Backside surface of the coxal endite (gnathobase) (C); Chelicera (D); Pedipalp chela (E)-right and lower hand photographs are enlarged observation of the squared areas; Tip and middle of leg (F and G)-lower hand photographs correspond to the squared areas; Tergite $(\mathrm{H})$. Genital opercula and pecten (I)-the right hand photograph shows an enlargement of the squared area; Sternite (J); Intraperitoneal contents (K); Metasoma and telson (L). Bar length: (A), (B), (E), (F), (G), (I), (K) and (L), 1 mm, high magnification photographs of (C), (D), (H), (J) and those of right and lower sides of (A), (E), (F), (G) and (I), $0.5 \mathrm{~mm}$. $a$ : carapace, $b$ : median eye, $c$ : lateral eye, $d$ : tubercular process, $e$ : chelicera, $f$ : coxa of leg, $g$ : coxal endite (gnathobase), $h 1$ : fine and silky hair of gnathobase backside surface, $h 2$ : brown long hair on the chelicera, $h 3$ : brown short seta on the pedipalp, $h 4$ : colorless short seta on the pedipalp, $h 5$ : trichobothrium on the pedipalp, $h 6$ : brown trichobothrium on the leg, $i$ : teeth on the chelicera, $j:$ pedipalp chela, $k$ : denticle row, $l$ : ungues on the leg telotarsus, $m$ : dactyl on the apotele, $n$ : tibial spur on the leg tibia, $o$ : keel, $p$ : genital opercula, $q$ : pecten, $r$ : marginal lamella and median lamella on the pecten, $s:$ pectinal tooth (comb-like structures of pecten), $t$ : spiracle, $u$ : telson, $x$ : vesicle, $y$ : aculeus.

In each leg segment (Figs. $2 \mathrm{~F}$ and $\mathrm{G})$, brown bristle hair (seta) (h6) was observed. The top of the seventh segment (telotarsus) was accompanied by one or two ungues $(l)$ and an apotele with a dactyl $(m){ }^{28)}$ Between one and three spurs (pedal spur, tibial spur $(n)$ ) could be observed at the end of the fifth and sixth segments.

Opisthosoma and Telson (Figs. 2H-2L) The dorsal side of the mesosoma was covered with blackish-brown tergites
(Fig. 2H). Remarkably, three lines of keel (o) were observed and reddish-brown tubercular processes $(d)$ were scattered on the surface. The ventral side was yellowish brown and covered with sternites (Figs. 2I and 2J), which were accompanied by genital opercula $(p)$, pecten $(q)$, and spiracles $(t)$. The pecten consisted of marginal and median lamellae $(r)$, fulcra, and pectinal tooth (comb-like structure) $(s)$. There were approximately twenty teeth in total. Pleural membranes 
were observed at the boundary of the tergites and sternites (no image). In domestic market products, come scorpions producing "Quanxie" contained tissues in the peritoneal cavity. Peritoneal tissues were yellowish-white globular substances (Fig. $2 \mathrm{~K}$ ), in some of which embryos initiated cell division, and/or blackish to whitish-gray fragile tissues. In samples from Vietnam, one of "Toàn yết" were almost empty, while the other was filled with whitish-gray fragile and sand-like materials in their peritoneal cavity.

The metasoma (Fig. 2L) consisted of five segments shaped like a barrel, the inside of which was almost vacant except for long black tissues thought to be muscles. The telson (Fig. 2L $(u)$ ), followed by the metasoma, was a small, round, brownish vesicle $(x)$ to which a reddish brown hooked aculeus $(y)$ was attached. Under the aculeus, no subaculear tubercle was found.

The following characteristics were determined by Takashima to be key to the identification of B. maretensii: 16-25 pectinal teeth, tibial spurs on the third and fourth legs, and a lack of subaculear tubercle. ${ }^{20-22)}$ Based on these criteria, it was concluded that the origin of the "Quanxie" drug samples used here was B. martensii.

Microscopic Characteristics of "Quanxie" (Fig. 3) Microscopic examination to determine the origin of crude drugs involves determining if the powdered materials are "fine powder" tissues and organs, and studying the microscopic morphology of the surface and cross-sectioned sides of each tissue and organ. Microscopic characteristics observed from every orientation are given below for the preparation of "Quanxie" standard reference photographs.

Although the microscopic morphology of the "Quanxie" has been already reported, ${ }^{10,24,25)}$ the names for each tissue in different reports are not the same. The appropriate names are given below in the descriptions of our observations.

Prosoma (Figs. 3A-3E) In the surface view of the outermost carapace layer (Fig. 3A-(1)), clear characteristic pentagonal or hexagonal border patterns were observed. Major and minor diameters of cuticle patterns were 11 to $16 \mu \mathrm{m}$ and 5 to $8 \mu \mathrm{m}$, respectively. Yellow shining tubercular processes (a) were scattered and many pore canals $(b)$ were found on the surface. At different depths of focus on the outermost layer, fine pores and a sinuous pattern emerged (Figs. 3A-(2), -(3) and -(4)). Most trichobothria had been removed and the double ring-shaped structure of socket cells was found at the base of the vestigial trichobothria (Figs. 3D-(1) and -(2)). In the transverse carapace section (Figs. 3A-(5) and -(6)), the outermost layer was an epicuticle $(c)$ with a brown exocuticle $(d)$, and an almost colorless longitudinal fibrous endocuticle (e) appeared underneath. Numerous parallel pore canals (b) penetrated through this layer. The outside tissues around the median eyes $(f)$ and lateral eyes $(g)$ were notable characteristics and the inside tissues were highly concave (Fig. 3A-(7)). Eyeballs were shiny yellow with orbicular elements (Fig. 3A-(8)).

The inner surface of the leg coxal endite (gnathobase) (Figs. 3B-(1) and -(2)) consisted of thinner tissue than the carapace cuticle. The gnathobase cuticle pattern was fuzzy and its surface was covered with numerous colorless hair (Fig. 3B-(1) (hl)). The diameters of the hair were 0.8 to $1.8 \mu \mathrm{m}$ and their length was approximately $60 \mu \mathrm{m}$, which was obviously finer than the hair on other parts. ${ }^{25}$ ) The base of the hair was circular and the vestige after the hair was removed was a small pore (Fig. 3B-(2)).

In the surface view of the chelicera coxa (Fig. 3C-(1)), the pattern of the epicuticle was slightly unclear. Pore canals $(b)$ and curved hair (h2) were scattered on the surface. Under a polarization field, the pore canals (Fig. 3C-(2)) shined in a cross pattern (Fig. 3C-(3)). The diameters and lengths of the hair were 6 to $10 \mu \mathrm{m}$ and 300 to $500 \mu \mathrm{m}$, respectively. Most hair were removed and the vestiges looked more like slightly larger circular pores than like pore canals. Chelicera chela (Figs. 3C-(4) and -(5)), accompanied by seta (h3) and reddish and round papillary processes $(i)$, were arranged in lines.

On the surface of the pedipalp cuticle (Fig. 3D), a clear border pattern consisting of numerous pore canals was observed. Trichobothria $(h 4)$ were scattered on the surface and the double ring structures derived from the socket cells were clear. In a surface view of the procuticle (paradermal section), a volute pattern was observed around the pores. In longitudinal sections of the chela and movable and fixed fingers of the sixth and fifth segments, large and small dark reddish-brown denticle processes, respectively, were lined up on the ventral sides (Fig. 3D-(3) $(j)$ ). Clear pore canals that passed through the cuticle and muscles $(k 1)$ were observed (Fig. 3D-(4)). Muscles were colorless or slightly light brown with clear striations. Individual fibers had a diameter of 17 to $50 \mu \mathrm{m}$ and formed bundles with diameters thicker than $100 \mu \mathrm{m}$.

In the surface view of the legs (Fig. 3E), the surface pattern on the cuticle was unclear in the first, second, sixth and seventh segments, but was clear from the third, fourth and fifth segments to the coxa. Trichobothria were densely distributed and arranged in lines $(h 5)$ on the sixth and seventh segments. In the transverse leg section, muscles were clearly observed. Larger muscles were found in the segments nearer the coxa (k2). In the interspace between the muscles and the cuticle, some tissues stained with Sudan III reagent (Fig. 3E-(3)). Ungues derived from the seventh segment and dactyls or spurs derived from other segments showed reddish spire-like and falciform shapes, and the tibial spurs of the third and fourth legs had the characteristic morphology of B. martensii.

Opisthosoma-Mesosoma (Figs. 3F and 3G) The surface view of the outermost layer of the tergite, sternite, and pleural membrane (Figs. 3F-(1), -(2) and -(3)) showed almost the same characteristics as the prosoma epicuticle. The cuticle pattern seen in the surface view of the sternites (Fig. 3F-(2)) was slightly unclear although it could be seen that the density of the tubercular processes was less than that of the tergites. In the transverse sections of tergites and sternites (Figs. 3F(4), -(5) and -(6)), circular muscle arranged circularly along the cuticle $(k c)$ and longitudinal muscle arranged vertically towards the cuticle $(k l)$ were observed. Sternites (Fig. 3F-(6)) had some spiracles and book-lungs $(o)$ consisting of many thin tissue layers.

The pleural membrane that connected to the tergites and sternites was constructed of a soft cuticle ${ }^{48)}$ and the surface view showed an irregular circular floral pattern (Fig. 3F-(3)). In the transverse section (Fig. 3F-(7)), the outmost layer was grayish green followed by a colorless, curved, wavy, longitudinal layer underneath. Adjacent to the pleural membrane, muscle was observed (Fig. 3F-(7) (k3)). Soft cuticle was observed not only in the pleural membrane but also in the genital opercula and in other tissues. In a longitudinal section of sternites (Fig. 3F-(8)), book-lungs were seen as stacks of 

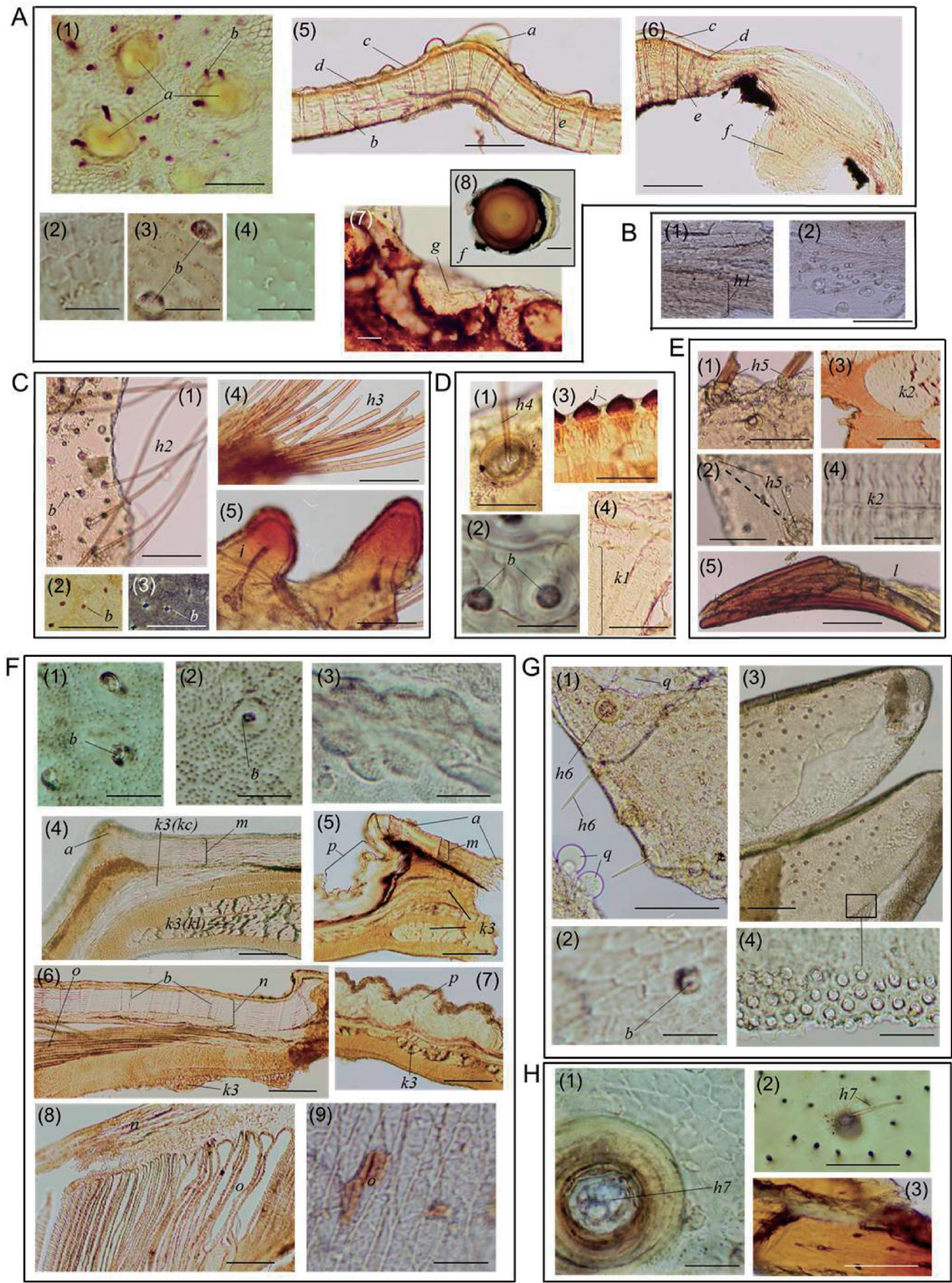

Fig. 3. Microscopic "Quanxie" Morphology

Carapace (A): (1) Surface view of the outermost cuticle layer; (2), (3), and (4) microscopic observations at different depths of the outermost layer; (5) and (6) transverse sections; (7) longitudinal sections of the lateral eyes; (8) surface view of the median eye. Bar lengths: (1), (5), (6), (7) and (8): 100 $\mu$ m; $(2-4)$ : 20 $\mu$ m. Coxal endite (gnathobase) (B): (1) and (2) Surface views of the coxal endite backside. Numerous colorless short hair $(h l)$ and vestiges (2) were observed. Bar length: $100 \mu \mathrm{m}$. Chelicera (C): (1) Surface view of chelicerae coxa; (2) and (3) surface views of pore canals under normal and polarized condition, respectively; (4) and (5) longitudinal chela sections. Anterior segment had numerous brown bristle hair (assumed to be seta). Bar length: $100 \mu \mathrm{m}$. Pedipalp (D): (1) and (2) Surface view of cuticle and procuticle, respectively; (3) and (4), longitudinal sections of chela, denticle row $(j)$ and muscle ( $k 1)$. Bar lengths: (1), (3) and (4): $100 \mu \mathrm{m}$; (2): $20 \mu \mathrm{m}$. Leg (E): (1) and (2) Surface views of the cuticle; (3) transverse section of the leg. Numerous muscles were observed and brownish regions were stained with Sudan III; (4) longitudinal section of the leg muscle; (5), ungues or dactyls on the leg telotarsus. Bar lengths: (1), (2) and (3) and (5): $100 \mu \mathrm{m}$; (4): $20 \mu \mathrm{m}$. Mesosoma (F): (1), (2) and (3) Surfaces view of the tergite, sternite and pleural membrane, respectively; (4), (5) and (6), transverse sections of the tergite and sternite; (7) transverse sections of a pleural membrane section; (8) longitudinal section of the sternite and book-lung; (9), surface view of the book-lung. Bar length: (1), (2) and (3) and (9): 20 $\mu \mathrm{m}$; (4), (5), (6), (7) and (8): 100 $\mu$ m. Pecten (G): (1) and (2) Surface view of marginal lamella on the pecten; (3) and (4) section of pecten piece. Bar lengths: (1) and (3): 100 $\mu \mathrm{m}$; (2) and (4) $20 \mu \mathrm{m}$. Metasoma and telson (H): (1) Surface view of the metasoma cuticle; (2) surface view of vesicle cuticle on the telson; (3) surface view of the aculeus cuticle. Bar lengths: (1): $20 \mu \mathrm{m} ;(2)$ and (3): $100 \mu \mathrm{m}$. $a$ : tubercular process, $b$ : pore canal, $c$ : epicuticle, $d$ : exocuticle, $e$ : endocuticle, $f$ : median eye, $g$ : lateral eye, $h 1$ : fine and silky hair on the gnathobase, $h 2$ : brown long hair on the chelicera coxa, $h 3$ : brown seta on the chelicera, $h 4$ : trichobothrium on the pedipalp, $h 5$ : trichobothrium on the leg, $h 6$ : seta on the pecten marginal lamella, $h 7$ : socket cell in the trichobothrium on the metasoma, $i$ : teeth on the chelicera, $j$ : denticle row of pedipalp chela, $k 1$ : pedipalp muscle, $k 2$ : leg muscle, $k 3$ : mesosoma muscle, $k c$ : circular muscle, $k l$ : longitudinal muscle, $m$ : tergite, $n$ : sternite, $o$ : book-lung, $p$ : pleural membrane, $q$ : oil drop. 
many thin tissue layer and the book-lung surface showed a flat rhomboid reticulate pattern (Fig. 3F-(9)).

On the marginal and median lamella of the pecten (Fig. 3G-(1)), bristle hair (h6), pore canals (Fig. 3G-(2) (b)) and cuticle patterns were observed. In some regions of these lamellae, film-like and flat pentagonal or hexagonal reticulate patterns (Fig. 3G-(2)) were observed with scattered oil drops $(q)$. In a transverse section of pectenal pieces showing comblike structures (Fig. 3G-(3)), the top shape was loosely curved and a series of circular pores along the marginal region were observed. Teeth had neither hair nor muscles. Since the tissues in the abdominal cavity were easily broken, it was hard to prepare slice sections for observation. The tissues from the abdominal cavity were therefore powdered and their morphology was observed later.

Metasoma and Telson (Fig. 3H) In the surface view of the metasoma (Fig. 3H-(1)), a clear cuticle pattern, shiny reddish-brown tubercular processes, trichobothrium with socket cells $(h 7)$, and pore canals were observed. Inside the metasomal cuticle, muscles were observed. Trichobothrium and pore canals were observed in the telson vesicle (Fig. $3 \mathrm{H}-$ (2)). The vesicle was vacant and had only a few muscles in it. The surface of the aculeus tip (Fig. 3H-(3)) was dark reddishbrown, spire-like, and falciform.

Microscopic Characteristics and Standard Reference
Microphotographs of Powdered Quanxie (Fig. 4) In order to prepare standard reference photographs for the identification of powdered crude drugs via microscopic observation, the whole dried body of "Quanxie" (Fig. 1A) was pulverized using a motor and pestle followed by sieving through stainless mesh $\left(\right.$ No. $50^{7)}$ ) and the resulting powders were mounted on slide glasses to be observed with a light microscope. The observed parts were grouped into appropriate tissues by comparison with the characteristic microscopic photographs of tissue sections shown in Fig. 3. The photographs of representative powder characteristics were arranged and summarized in Fig. 4 as tissue fragments mainly derived from cuticle or epidermal system (Fig. 4A), seta and trichobothrium (Fig. 4B), muscles (Fig. 4C), and other parts (Fig. 4D). The parts with morphologies useful for identification of the origin of the tissue as $B$. martensii were observed at high magnification, as shown in Fig. 4E.

Carapace cuticle and its enlarged view are shown in Figs. $4 \mathrm{~A}-a$ and $4 \mathrm{E}-a$. Observation at high magnification showed the cuticle pattern (Fig. 4E- $a-1$ ), socket cells (Fig. 4E-a-2), pore canals (Fig. 4E-a-3), tubercular process (Fig. 4E- $a-4$ ), and a fine cuticle pattern (Fig. 4E- $a-5$ ). Cuticles derived from gnathobase (leg coxal endites) were observed as fragments covered with colorless, fine, straight hair (Figs. 4A- $b$, 4E- $b-1$ and $4 \mathrm{E}-b-2)$. Cuticles derived from the chelicera were reddish-
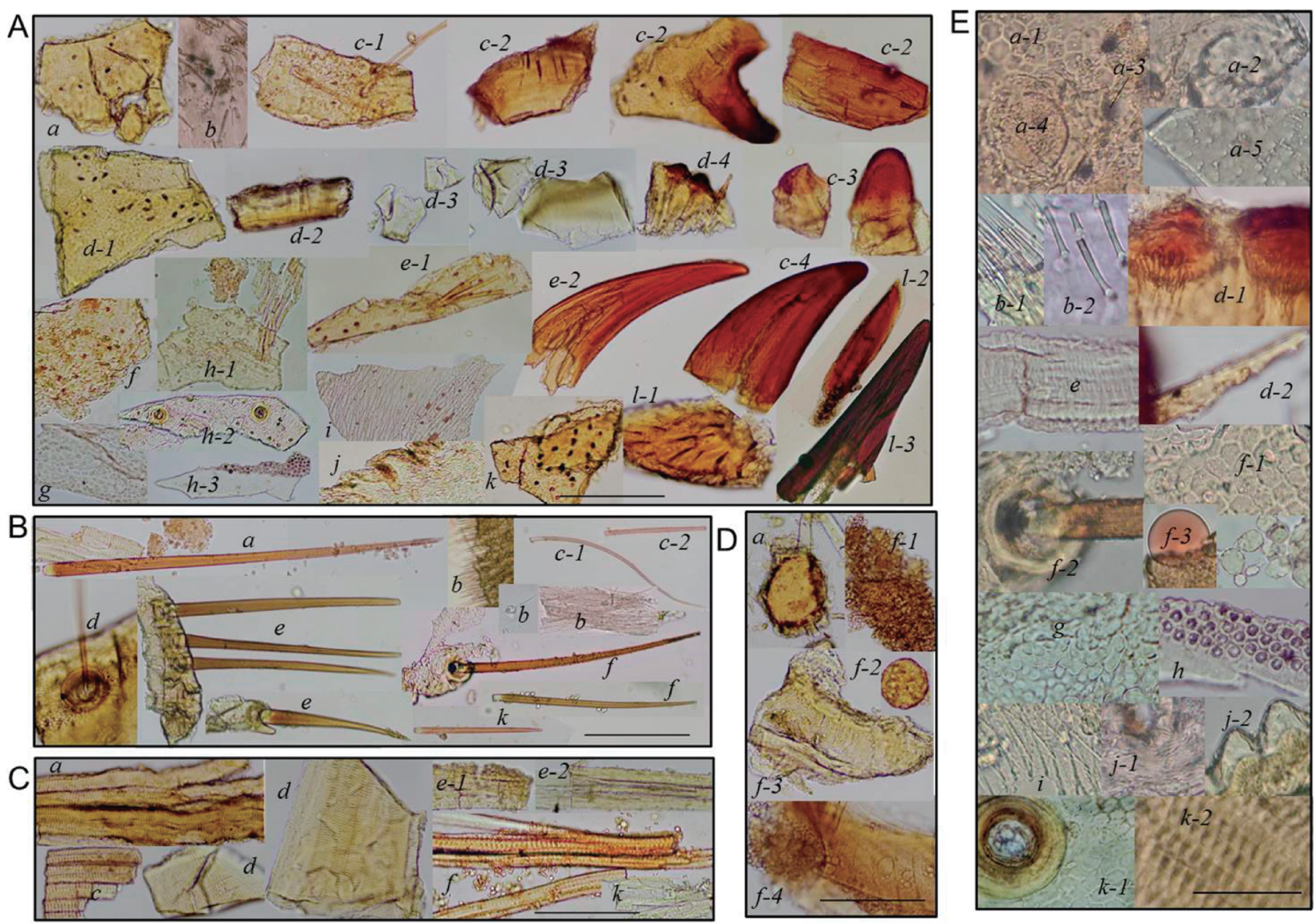

Fig. 4. Standard Reference Microphotographs of Powdered "Quanxie"

Fragments derived from cuticle or epidermal systems (A). Hairs (seta and trichobothrium) (B). Fragments derived from muscle (C). Fragments derived from other tissues (D). High magnified photographs of characteristic and important morphologies useful for identifying the origin of $B$. martensii-derived tissues (E). Small italicized letters refer to the tissue origin and hyphenated numbers represent different micro-morphology characteristics in samples derived from the same origin of tissues. Bar lengths: (A-D): $200 \mu \mathrm{m}$; (E): $50 \mu \mathrm{m}$. Fragments derived from $a$ : carapace, $b$ : gnathobase, $c$ : chelicera, $d$ : pedipalp, $e$ : leg, $f$ : mososoma, $g$ : genital opercula, $h$ : pecten, $i$ : book-lung, $j$ : pleural membrane, $k$ : metasoma, $l$ : telson. 
brown and had numerous slightly curved hair (Figs. 4A-c-1 and $4 \mathrm{~A}-c-2)$. Papillary processes accompanied by a reddishbrown tip (Fig. 4A-c-3) were characteristic of chelicera, which were observed as single and multiple rows and were derived from two anterior chela-forming segments. Fragments derived from the chela tip were dark reddish-brown and appeared in a falciform shape (Fig. 4A-c-4). Most pedipalp cuticles appeared in the surface view under microscopic observation (Fig. 4A$d-1)$ and some fragments were observed in the cross-section (Fig. 4A-d-2). Some procuticle fragments were observed as shiny plate-like layers (Fig. 4A- $d-3$ ). Reddish brown processes derived from denticle rows of the sixth (tarsus, movable finger) and the fifth (tibia, fixed finger) segments appeared as single and multiple rows of processes (Figs. 4A- $d-4$ and $4 \mathrm{E}-$ $d-1)$. Fibrous connections from these processes to other tissues through the cuticle might be sensory tissue (Fig. 4E- $d-1$ ). Cuticle derived from the legs (Fig. 4A-e-1) had trichobothria arrayed on a straight line. Ungues and dactyls were observed as reddish spire-like and falciform fragments (Fig. 4A-e-2). Although the shape of ungues and dactyls were similar to each other and the powder preparations were difficult to distinguish, in the external morphology dactyls are less curved than ungues. The width of the ungues and dactyls (Fig. 4A$e-2$ ) was generally narrower than that of the chela tip (Fig. $4 \mathrm{~A}-c-4$ ). Cuticles derived from tergites and sternites (Figs. $4 \mathrm{~A}-f$ and $4 \mathrm{E}-f-1$ ) had trichobothria with clear socket cells (Fig. $4 \mathrm{E}-f-2)$ and some of them included oil drops stained with Sudan III reagent (Fig. 4E- $f-3$ ). Characteristics of the tergite cuticles were similar to those of the sternites, but they were distinguishable by the slightly unclear cuticle pattern found in the sternites, a higher density of tubercular process found in the tergites, and the fact that some sternite fragments were accompanied by book-lungs. Genital operculum was a tiny tissue associated with soft cuticle with particular pattern (Figs. $4 \mathrm{~A}-g$ and 4E-g). Some cuticle fragments derived from basal pectenal pieces showed a slightly flat pentagonal or hexagonal reticulate pattern, the socket cells derived from which were smaller than those derived from other tissues (Fig. 4A- $h-1$ ). In the cuticle fragments of cuticle derived from pectinal teeth (comb-like structure), many circular pores were densely arranged along the marginal region (Figs. $4 \mathrm{~A}-h-3$ and $4 \mathrm{E}-h$ ). Epidermal cells in the book-lung, which is an organ specific to arachnida, were film-like structures with a flat rhomboid reticulate pattern (Figs. 4A- $i$ and 4E- $i$ ). The pleural membrane was made up of amorphous fragments of soft cuticle with irregular circular and floral patterns (Figs. 4A-j, 4E-j-1 and 4E-j-2). The genital operculum, pleural membrane, and the intersegmental membrane consisted of soft cuticles and showed similar characteristics to each other. Fragments derived from cuticles of the metasoma and telson were darker red than those derived from other tissues (Fig. 4A-k) and the large socket cells were found on the surface (Fig. 4E-k-1). The cuticle derived from vesicle was dark reddish brown (Figs. 4A-l-1 and 4A-l-2). The tip of the aculeus was also colored dark reddish brown and was not curved but sharp (Fig. 4A-l-3).

Most tissue fragments identified as hair were derived from the seta and trichobothrium (Figs. 4B and 4E). Some hair (trichobothrium) accompanied a cuticle attached to a socket cell with a double ring-like shape. Hair (trichobothrium) of the carapace was reddish brown and had vertical lines on the surface (Fig. 4B-a). Two types of hair on the gnathobase
(Fig. 4B- $b$ ) were observed; one was very fine with a sharp top (Fig. 4E- $b-1$ ) and the other was not (Fig. 4E- $b-2$ ). Chelicera hair showed two types of shapes, one soft curved and the other rectilinear with a difficult-to-see lumen (Figs. 4B-c-1 and 4B-c-2). Pedipalp trichobothrium also showed two types of shapes, where one was similar to those of the carapace and the other was a fine seta with a socket cell (Figs. 4B-d and $4 \mathrm{E}-d-2)$. Multiple trichobothria of legs arranged in a line could be observed (Fig. 4B-e). Most hair on the mesosoma was brownish with vertical stripes (Figs. 4B- $f$ and $4 \mathrm{E}-f-2$ ), but some of them were colorless and short. Hair from metasoma was similar to those of mesosoma but their lumen was clear (Fig. 4B-k).

Muscles were derived from almost all tissues and were observed in large amounts of pulverized fragments (Fig. 4C). They were colorless to yellowish brown with clear striations and appeared separately or as bundles. Some muscles derived from the carapace appeared to be attached to the eye ball or other tissues (Figs. 4C- $a$ and 4D- $a$ ). Pedipalp muscles were composed of bundles larger than $100 \mu \mathrm{m}$ in diameter (Fig. 4C$d)$. In the legs, some muscles had striations (Figs. 4C-e-1 and $4 \mathrm{E}-e$ ) and some did not (Fig. 4C-e-2). Muscles derived from the mesosoma developed better in the ventral side than in the dorsal side and appeared as elongated fragments (Fig. 4C-f). Some muscles derived from metasoma were almost colorless (Figs. 4C- $k$ and $4 \mathrm{E}-k-2$ ).

Other sections appeared as major observed objects (Fig. 4D) and may have been the tissues in the peritoneal cavity, which seen to be colorless or yellowish-brown granules with single or spherical lumps (Fig. 4D-f-1) containing oil drops stained with Sudan III (Fig. 4D-f-2). Other tubular tissue fragments (Figs. 4D-f-3 and 4D-f-4) were thought to be derived from other gastrointestinal organs.

Fluorescence Fingerprint Analysis of "Quanxie" and of Other Crude Drugs Derived from Insect Origins The fluorescence fingerprint method involves scanning a sample for a continuous wavelength of emission light and recording the luminescence intensity of the fluorescence at a continuous excitation wavelength. The results are presented as three-dimensional graphs of luminescence intensity at varied emission wavelengths and excitation fluorescence (Fig. $5 x$ - and $y$-axes, respectively). The samples for the fluorescence spectrometer were mounted as solid materials irrespective of shape such as fragmented cut bodies and powders. "Quanxie" gave strong fluorescence upon UV light illumination (Fig. 1A(2)) and its coarse powders showed remarkable fluorescence (Fig. 1E). In order to prepare crude drugs for medication, whole or cut bodies of "Quanxie" are pulverized into powders. The representative fluorescence fingerprint profile of "Quanxie" powders prepared from a whole body is shown in Fig. 5A. The graphs on the left-hand side of Fig. 5 show the contour lines of luminescence intensity, while the upper and lower right-hand graphs show two-dimensional spectrograms at the peak luminescence intensities for fixed excitation and emission wavelengths, respectively. The data given are the maximum luminescence intensities derived from the fluorescence spectrophotometer at peak excitation/emission light wavelengths. Powders of whole bodies of "Quanxie" showed remarkably high emission peaks at approximately $490 \mathrm{~nm}$ when irradiated with $400 \mathrm{~nm}$ (Fig. 5A). Almost identical fingerprint profiles showed a peak at $480-490 \mathrm{~nm}$ emission light against $400 \mathrm{~nm}$ excitation light in 
A Quanxie

$\lambda_{E X} / \lambda_{E M}: 400 / 490 \mathrm{~nm}$, Data: 87.81
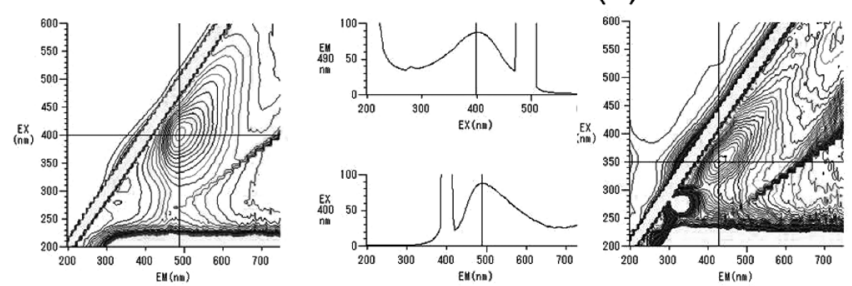

B Chantui

(1) $\lambda_{E X} / \lambda_{E M}: 350 / 430 \mathrm{~nm}$, Data : 31.31

C Sangpiaoxiao

$\lambda_{E X} / \lambda_{E M}: 450 / 565$ nm, Data : 26.30

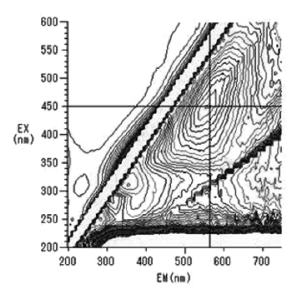

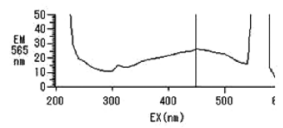

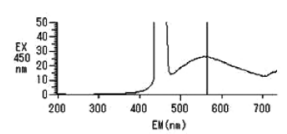

D Jiangcan
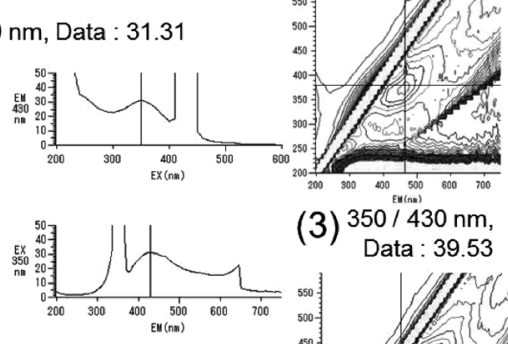

(3) $350 / 430 \mathrm{~nm}$

$380 / 465 \mathrm{~nm}$,

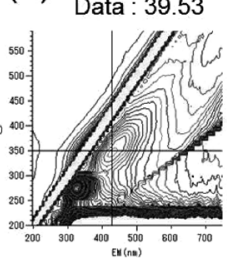

Fig. 5. Fluorescent Fingerprint of "Quanxie" and Other Crude Drugs Derived from Arthropods

Powder of whole bodies of "Quanxie" (Uchida-Wakanyaku Ltd.) (A). Powder of whole bodies "Chantui" (B): (1) Powder of whole slough; (2) Powder of eye part; (3) Powder of thorax part. Powder of "Sangpiaoxiao" surface layer (C). Powder of "Jiangcan" surface layer (D). The left-hand diagrams (A-D) show contour lines of luminescence intensity versus emission and excitation wavelengths of $x$ - and $y$-axes, respectively. The right upper diagrams show the luminescence intensity of excitation spectra and the lower diagrams show emission spectra at the peak excitation wavelengths. Data represent the value of luminescence intensity output from the fluorescence spectrophotometer at the peak excitation and emission wavelengths. Contour line interval: (A), 5; (B)(1), (B)(2) and (C), 1; (B)(3) and (D), 2.

powders of different "Quanxie" products obtained from Japanese wholesalers of crude drugs (Supplementary Fig. 1). These profiles might be reflected by the fluorescence observed for "Quanxie" (Fig. 1A(2)) and the powders of surface cuticles of each part of mesosoma or metasoma showed remarkably high emission peaks at $480-490 \mathrm{~nm}$ when irradiated with $400 \mathrm{~nm}$ (Supplementary Figs. 2A and 2B). Compared to surface side of outer tissues visible in the outside, we found that the tissues inside the peritoneal cavity in "Quanxie" purchased from Japanese wholesalers exhibited fluorescence at approximately $550 \mathrm{~nm}$ after irradiation at $450 \mathrm{~nm}$ (Supplementary Figs. 2C(1), -(2) and -(3)). "Toàn yết" acquired from Vietnam exhibited strong fluorescence image at outside (Fig. 1A) and similar fingerprint profiles for powders of mesosoma and metasoma parts to those obtained from Japanese wholesalers; the powder of sand-like materials in the peritoneal cavity of "Toàn yết" did not exhibit a remarkable fluorescence fingerprint profile (Supplementary Fig. 2C-(4)), indicating that these materials might be different the from intraperitoneal tissues inside the peritoneal cavity of "Quanxie" obtained from Japanese wholesalers.

Since other insect crude drugs, "Chantui," "Sangpiaoxiao" and "Jiangcan" showed fluorescence upon illumination with UV-light (Fig. 1), powders of these crude drugs prepared by pulverization of whole bodies were mounted in the fluorescence spectrometer. We succeeded in observation of the fingerprint profile of the powders of "Chantui" whole bodies (Fig. 5B), but failed in that of "Sangpiaoxiao" and "Jiangcan" (data not shown). This might be because "Chantui" consists of molten skins of cicada without any tissues inside and the powders are composed of parts of cicada slough with less contamination from materials interfering with fluorescence as observed in Fig. 1F. "Sangpiaoxiao" and "Jiangcan" are egg cases of mantis and bodies of sick silkworm, respectively, in which large amounts of internal tissues contaminate the powder preparation of whole bodies of crude drugs and interfere and/or quench fluorescence derived from surface parts as observed in Figs. $1 \mathrm{G}$ and $\mathrm{H}$, respectively. The fingerprint profile of whole "Chantui" slough showed an emission peak at $430 \mathrm{~nm}$ after irradiation at $350 \mathrm{~nm}$, but the luminescence intensities, 31.31, were smaller than those of "Quanxie," 87.81 (Figs. 5A and B-(1)). In the body, remarkable fluorescence was observed at eye and thorax part (Fig. 1F). Characteristic emission peaks were found in the eye and thorax of "Chantui" at $465 \mathrm{~nm}$ emission after irradiation at 380 and at $430 \mathrm{~nm}$ emission after irradiation at $350 \mathrm{~nm}$ (Figs. $5 \mathrm{~B}(2)$ and $5 \mathrm{~B}(3)$, respectively), indicating that the fingerprint profiles observed for the powders of "Chantui" whole bodies might be majorly caused by the fluorescence exhibited by the powder of these parts. Although remarkable fingerprint profiles could not be obtained for the whole bodies of "Sangpiaoxiao" and "Jiangcan," the parts of surface layer shaved and collected from these bodies, for which the fluorescence could be observed as shown in Figs. $1 \mathrm{G}$ and $\mathrm{H}$, exhibited a typical fingerprint profile of fluorescence; "Sangpiaoxiao" had an emission peak at approximately $565 \mathrm{~nm}$ after excitation at $450 \mathrm{~nm}$ and "Jiangcan" had emission peaks at approximately 465 and $535 \mathrm{~nm}$ after excitation at 370 and $450 \mathrm{~nm}$, respectively, both of which showed different patterns compared from "Quanxie" and "Chantui" and lower luminescence intensities than "Quanxie." 

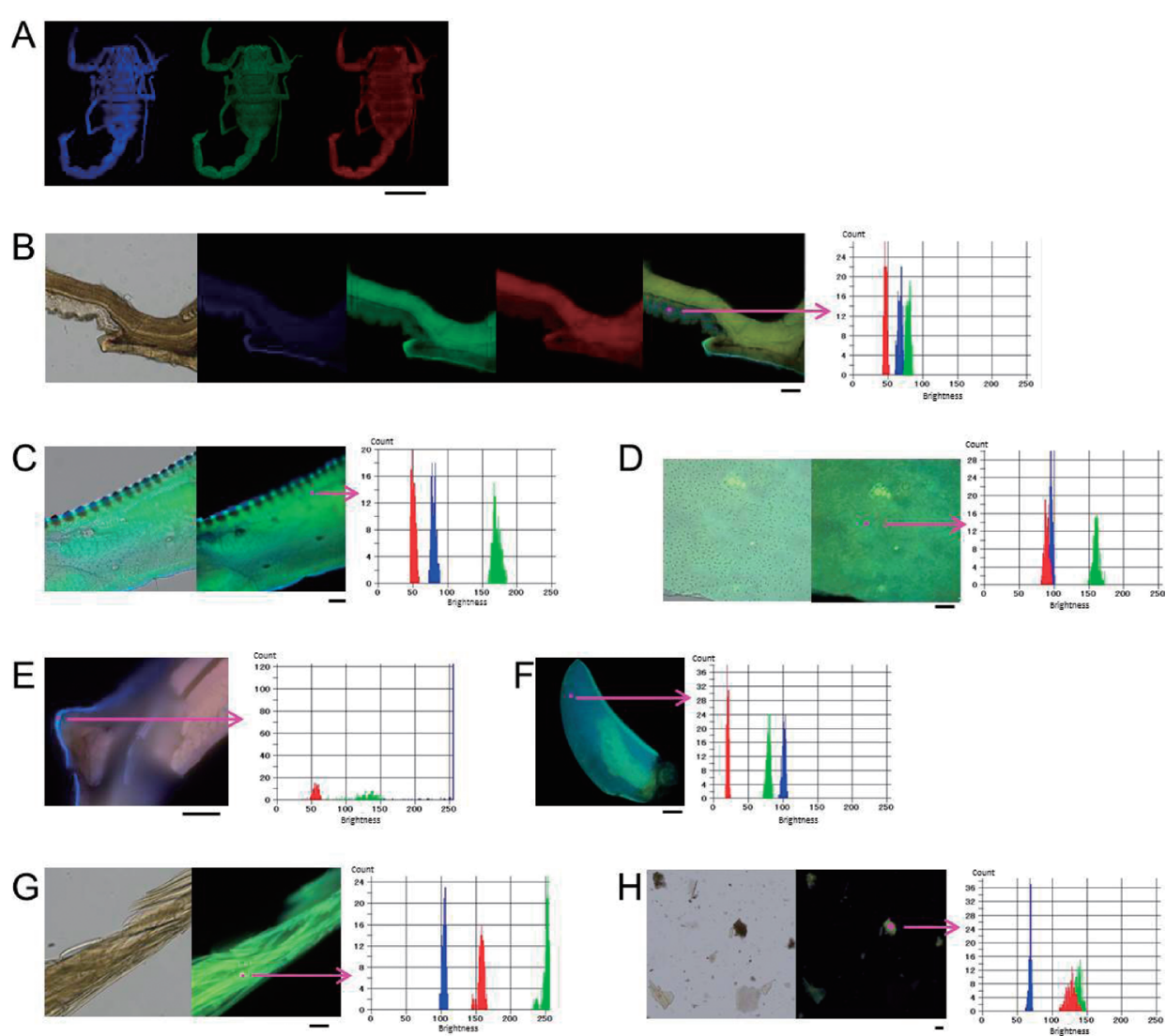

Fig. 6. "Quanxie" Observed with a Fluorescence Microscope and Fluorescent Luminance Imaging Analysis for Brightness at Pixel Level

Composite fluorescence images (sum of sixty scans) of a whole "Quanxie" body with excitation at 340-380, 450-490, and 532.5-557.5 nm then observed through DAPI, GFP, and TRITC filters (A, left, center, and right, respectively). Cross-section of the tergite area (B): images under visual light (left) observed through DAPI, GFP and TRITC filters (second, third, and fourth photographs, respectively), and a merged photograph (the right end of photographs). Fluorescence brightness was independently derived from three filters at the point indicated by the pink square $\left(13 \times 13 \mathrm{pix}^{2}=\mathrm{B}, \mathrm{C}, \mathrm{D}, \mathrm{F}, \mathrm{G}, 20 \times 20 \mu \mathrm{m}^{2}, \mathrm{E}, 10 \times 10 \mu \mathrm{m}^{2}, \mathrm{H}, 50 \times 50 \mu \mathrm{m}^{2}\right)$. Fluorescence was observed using a CCD camera attached to the fluorescence microscope and the number of counts observed through each filter was plotted to obtain the brightness (DAPI, GFP, and TRITC filters for blue, green, and red histograms, respectively). Surface view of the pedipalp and sternite (C and D): overlay image of fluorescence with the three filtered lights (right) and further merged with visible light image (left). Merged image of three fluorescent images of tergite and pectinal tooth cross sections (E and F). Longitudinal section of muscle and fragmented intraperitoneal contents ( $\mathrm{G}$ and H): images under visible light (left) and overlay of three fluorescent images (right). Bar lengths: (A): $1 \mathrm{~cm} ;(\mathrm{B})$ to $(\mathrm{H}): 100 \mu \mathrm{m}$.

Microscopic Fluorescent Luminance Imaging Analyses of "Quanxie" Powdered Fragments Distinguishable from Other Insect Derived Materials Since scorpion bodies fluoresce after irradiation with approximately $380 \mathrm{~nm}$ light (Fig. 1A), the emitted light gave characteristic fluorescence images when viewed through DAPI, GFP, and TRITC filters (Fig. $6 \mathrm{~A})$. In the slice preparation, we could observe that the epicuticle fluoresced blue and the procuticle fluoresced green. These properties were used to characterize "Quanxie" using a fluorescence microscope attached to a 2.38-million-pixel monochrome CCD camera and analyzed using BZ-X Analyzer software (Keyence). Figure 6B shows a representative resultant photograph and histogram of the pleural membrane section. Observation by visual light (Fig. 6B, photograph furthest to the left) was used for the identification of micro-morphological characters and, in the same view field, observation through fluorescent light through individual DAPI, GFP, and TRITC filters (Fig. 6B, the second, third and fourth of photographs from the left, respectively, and the fifth was overlay of these three photographs) gave characteristic information about the tissues. The individual images were taken with a CCD camera and the fluorescence brightness of specific pixels (shown as the pink squares in the following figures) was analyzed and overlaid into a histogram (Fig. 6B right) by the software with blue, green, and red bars corresponding to images derived from DAPI, GFP, and TRITC filters, respectively. In the tergite area, the pleural membrane was more transparent under visual light on the lower left side of the specimen (Fig. 6B). In the observation of these images by individual filters to the view field, any point of objective area of $20 \times 20 \mu \mathrm{m}^{2}$, which corresponded to $13 \times 13$ pix $^{2}$ in CCD camera image, could be selected. Several pixel square points of different areas in an identical view field were designated to measure fluorescence brightness. Our detailed histogram-based observations that surveyed several points of the tergite area revealed that similar histogram profiles could be observed in separate, individual areas of homogenous cells (Supplementary Fig. 3).

The visual and fluorescence overlay photographs for surface views of the pedipalp and sternite samples are shown in Figs. $6 \mathrm{C}$ and $6 \mathrm{D}$. In these regions, the green color was very brightness and the histograms at the pixel point showed higher quantified results for the green brightness than for blue or red. For the cross-section view of the sternite, the epicuticle in particular shined bright blue with remarkable fluorescence (Fig. $6 \mathrm{E})$. The histogram, therefore, showed a high value for the brightness of the blue color. The surface of pectinal tooth was also observed to fluoresce blue (Fig. 6F). Muscle (Fig. 6G) and intraperitoneal tissues (Fig. $6 \mathrm{H}$ ) had high values for brightness 

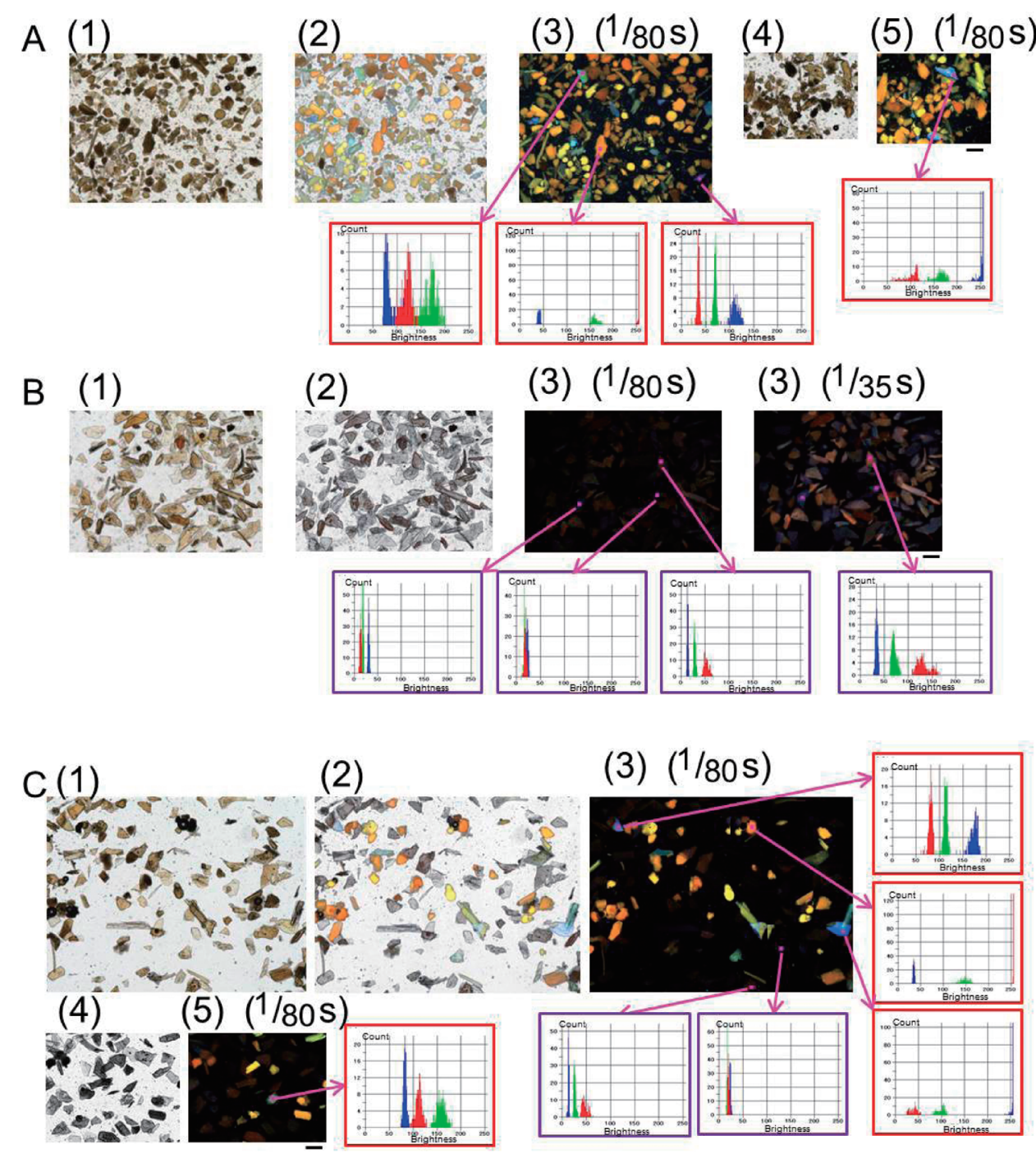

Fig. 7. Powdered "Quanxie" and "Chantui" Observed with a Fluorescence Microscope and Fluorescent Luminance Imaging Analysis

Powdered "Quanxie" (Uchida-Wakanyaku Ltd.) (A); Powdered "Chantui” (B); Mixture of "Quanxie" and "Chantui” powders (1:1, w/w) (C). A-(1), A-(4), B-(1), C-(1), and C-(4) show powders observed with visible light; A-(2), B-(2), and C-(2) show overlays of merged visible light images with three fluorescence images observed through DAPI, GFP, and TRITC filters (Excitation: 340-380, 450-490, and 532.5-557.5 nm, respectively); A-(3), A-(5), B-(3), C-(3), and C-(5) show merged images of three fluorescence images. Exposure times were $1 / 80$ and $1 / 35 \mathrm{~s}$. Histograms show the distribution of the brightness for the fluorescence observed through DAPI (blue bars), GFP (green bars), and TRITC (red bars) filters in the areas indicated by the pink squares $\left(13 \times 13 \mathrm{pix}^{2}=50 \times 50 \mu \mathrm{m}^{2}\right)$. Red and purple framed histograms were determined to be fragments derived from "Quanxie" and "Chantui," respectively. Bar length: $200 \mu \mathrm{m}$.

of green and red and some were observed as yellow to brown. In the preparation of the standard reference photographs from the powdered materials mentioned in the previous section, intraperitoneal contents were frequently observed, suggesting that this particle-like material might be a good marker to identify "Quanxie" using microscopic fluorescent luminance imaging analysis.

In the "Quanxie"-derived powders (Fig. 7A), fragments shined blue and yellow under the fluorescence microscope. In particular, many yellowish fragments were observed in "Quanxie" from Uchida-Wakanyaku Ltd. which contained a lot of intraperitoneal contents (Fig. 7A). In contrast, there were many fragments that shone blue in the Vietnam commercial brand "Toàn yết" powder (Supplementary Figs. 4A and B). In the bluish fluorescent fragments found in the powders, the distribution of brightness of each color depended on which tissues each fragment derived from; the fragments showing strong blue brightness were likely derived from the epicuticle and those showing strong green brightness could be from the pedipalp, sternite or muscle.

The powders derived from "Chantui" fluoresced only weakly under irradiation with light that generated a strong response from "Quanxie." In order to strengthen the weak fluorescent brightness of "Chantui" fragments, a long exposure time, $1 / 35 \mathrm{~s}$, was required, as compared to an exposure time of $1 / 80 \mathrm{~s}$ for "Quanxie" (Fig. 7B). The brightness histogram after $1 / 80 \mathrm{~s}$ exposure showed that the weak fluorescence distributed at lower range in "Chantui" than that in "Quanxie" (compare Figs. 7A-(3) and B-(3). A few fragments fluoresced blue and other major fragments fluoresced almost red in "Chantui" powder after $1 / 35 \mathrm{~s}$ exposure (Fig. 7B-(3)(1/35s)); an abundance of blue-fluorescing fragments was observed in the thorax sample (Supplementary Fig. 4C). Since "Sangpiaoxiao" and "Jiangcan" powders fluoresced less brightly, exposure times of $1 / 25$ and $1 / 35 \mathrm{~s}$, respectively, were necessary to take photographs with enough quantifiable data to produce histograms. Many fragments that showed strong brightness values for red and green in the histograms looked as though they 
fluoresced yellow in microscopic photographs (Supplementary Figs. 4D and 4E).

When "Quanxie" and "Chantui" powders were mixed 1:1 (w/w), they are distinguishable, since the brightness of fluorescence derived from "Quanxie" tissue was apparently higher than that from "Chantui" (Fig. 7C). In addition, the histogram pattern by the fluorescent luminance imaging analysis could provide the even origin of individual fragments as being from either "Quanxie" or "Chantui."

\section{DISCUSSION}

Recent advances in molecular biological and phytochemical methods have provided new molecular phenotype markers. Molecular biological phenotypes using PCR and nucleotide sequences and phytochemical phenotypes determined by HPLC, TLC, and MS are useful to identify the constituent materials and origins of crude drugs. Microscopic examination methods have been traditionally used since they are convenient, fast, and require small amounts of materials to identify the origin of crude drugs. The specimens that require microscopic observation are usually chopped, broken, cut, fragmented, or powdered and then mounted on glass slides, after which the micromorphological characteristics can be difficult to use to distinguish between animals and plants, unless the observer knows individual characteristics. In microscopic observations of powdered crude drug preparation, many similar figures that were observed derived from completely different organisms including sometimes both insects and plants. In order to identify the ingredients found in a preparation of crude drugs containing plant and animal origins, detailed and accurate observation of the fragment characteristics is required and the standard reference photographs must be prepared.

The respiration systems of arachnida consist of trachea and/or book-lungs. Some arachnida have only trachea and others have both trachea and book-lungs, which they use depending on the environmental conditions. ${ }^{28,45,46)}$ Scorpions have no trachea but respire using four pairs of book-lungs attached at spiracles on the third, fourth, fifth, and sixth sternites. ${ }^{27,28,45,46)}$ Scorpions are known to have evolutionarily conserved relatively primitive organs such as book-lung. The microscopic characteristics of book-lung tissue observed here and in the standard reference photographs might be useful for the identification of scorpions in powdered crude drugs.

Scorpion cuticle is known to emit fluorescence. Fluorescence fingerprinting is advantageous over other analytical methods since that solid materials, such as whole bodies, exfoliated exoskeletons, and powdered materials, can be analyzed and recovered after the analysis. Fluorescence was also observed in the "Chantui," "Sangpiaoxiao," and "Jiangcan" samples, but their fluorescence fingerprint profiles differed from those of "Quanxie." Since the fluorescence fingerprint profiles of separate classes might be expected to differ, the fluorescence fingerprint method was applied to identify crude drugs derived from arachnida. Pandinus imperator (emperor scorpion) fluoresced at $500 \mathrm{~nm}$ after irradiation at $365 \mathrm{~nm}$ and other scorpions showed similar species-specific fluorescence after species-specific excitation wavelengths. ${ }^{35,51)}$ These facts added to our results presented here support the conclusion that fluorescence fingerprinting may be useful for the identification of Buthidae. The data presented here are insufficient for perfect identification of individual Buthidae species. Significantly more fingerprint profile data are going to be measured to establish macroscale identification methods comparable to micro-morphological identification. In this study, we obtained preliminary results that a mixture of "Quanxie" and "Chantui" powders showed different emission values at specified emission wavelengths. This suggests that the fingerprint method may be useful to qualitatively and quantitatively identify crude drugs mixture with powder materials composed of different species origins.

While the fluorescence fingerprint method could play an effective role in identifying "Quanxie" at the macro-level when accompanied by macro-morphology data (Fig. 1), fluorescence microscopy could be a useful and powerful tool to survey the observed microscopic field and identify "Quanxie" using microscopic level data. Coupling fluorescence microscopy with a CCD camera followed by imaging analysis, the targeted regions of organs, tissues, and individual powdered fragments could be analyzed to determine their distinct fluorescences at three different fluorescence wavelengths. These data were then quantitatively presented as histograms. The merit of fluorescence microscopy observation was that fragments that fluoresced could be detected in a large number of objects under low-magnification. When one fragment in the powdered crude drug mixture was detected under the low-power field, its micro would be observed in a high-power field and then be compared with standard reference to identify its origin. When one fragment could be identified as originating from a certain "Quanxie" tissue or organ, further microscopic fluorescent luminance imaging analysis could then provide more reliable identification by comparing to reference histogram profiles, if they were available. Future detailed experiments to prepare references standard histogram profiles of all of individual tissues and organs of "Quanxie" should be conducted.

The fluorescence fingerprint and microscopic fluorescent luminance imaging analysis methods established here are an important breakthrough to have accurate, prompt, and convenient identification methodologies for crude drug identification. These methods will be able to identify crude drugs originated from many species, including "Quanxie," when the necessary databases of the standard references of fluorescence fingerprint profiles and microscopic fluorescent luminance histograms are ready.

Acknowledgments We thank Mr. Kiyoshi Sugiyama and Dr. Takuro Maruyama for providing Vietnam and domestic market products and Dr. Naoko Sato for guidance and advice on measuring fluorescence fingerprints. We thank Dr. Nahoko Uchiyama for valuable experimental suggestions. We thank Mr. Hideki Nishikawa, Keyence Corporation, for cooperation in observation using Bz-X700 and for analytical advice. This work was partially supported by Health Labour Sciences Research Grant from the Ministry of Health, Labour, and Welfare.

Conflict of Interest The authors declare no conflict of interest.

Supplementary Materials The online version of this article contains supplementary materials. 


\section{REFERENCES}

1) Liang YZ, Xie P, Chan K. Quality control of herbal medicines. J. Chromatogr. B Analyt. Technol. Biomed. Life Sci., 812, 53-70 (2004).

2) Montoro P, Piacente S, Pizza C. Quality issues of current herbal medicines. Herbal Medicines. Development and Validation of PlantDerived Medicines for Human Health. (Bagetta G, Cosentino M, Corasaniti MT, Sakuraba S eds.) CRC Press, Boca Raton (2011). ISBN 978-1-4398-3769-6 (2016).

3) Shaw PC, Wang J, But PP-H. Authentication of Chinese Medicinal Materials by DNA Technology. World Scientific Publishing Co. Pye. Ltd. (2002). ISBN 978-981-02-4621-1.

4) Joshi K, Chavan P, Warude D, Patwardhan B. Molecular markers in herbal drug technology. Curr. Sci., 87, 159-165 (2004).

5) Jackson BP, Snowden DW. Atlas of Microscopy of Medicinal Plants, Culinary Herbs and Spices. CRC Press, Boca Raton (1990). ISBN 0-8493-7705-6.

6) Upton R, Graff A, Jolliffe G, Länger R. Microscopic Characterization of Botanical Medicines (American Herbal Pharmacopoeia Botanical Pharmacognosy). CRC Press, Boca Raton (2011). ISBN 978-1-4200-7326-3.

7) Ministry of Health Labour and Welfare. The Japanese Pharmacopoeia 17th ed. (Ministry Notification 64). Japan, p. 4 and pp. 120-121 (2016).

8) Chinese Pharmacopoeia Committee of Ministry of Public Health of the People's Republic of China. Chinese Pharmacopoeia Vol. 1 The People's Health Publishing House, People's Republic of China, p. 143 (2015).

9) Chinese Materia Medica. (Jiangsu New Medical College ed.) Shanghai People's Publication House, People's Republic of China, pp. 1288-1291 (2006)

10) Xu G-J. Chinese Materia Medica, China Medical Science Press, People's Republic of Chaina, pp. 1780-1782 (1996).

11) Namba T. The Encyclopedia of Wakan-Yaku (Traditional Sino-Japanese Medicines) with Color Pictures Vol. II. Hoikusha Publishing Co., Ltd., Japan, pp. 259-261 (1980). ISBN: 4586302046

12) Suzuki T. Studies of various editions of "Heji Jufang" and objective of compilations of "Heji Jufang" during the Kyoho era of the Edo period. Jpn. J. History Pharm. Yakushigaku Zasshi, 42, 91-96 (2007).

13) Shimomura H, Tokumoto $H$, Sekita S, Satake M, Tokugawa M, Tokugawa N, Goda Y. Identification of components in "Usaien" preparation: contents of the heirloom gallipot of the Mito-Tokugawa family. J. Nat. Med., 67, 41-58 (2013).

14) Koch CL. Buthidae. "The Scorpion Files": 〈https://www.ntnu.no/ub/ scorpion-files/buthidae.php> Jan. 13, 2017.

15) Pocock RI. The Fauna of British India. "The Scorpion Files": 〈https:/www.ntnu.no/ub/scorpion-files/pocock_fauna_india2.pdf〉, 1900. Dec. 19, 2017.

16) Vachon M. Etudes sur les Scorpions. "The Scorpion Files": 〈https:/www.ntnu.no/ub/scorpion-files/vachon2.pdf〉, 1952. Dec. 19, 2017.

17) Pavlovsky EN. Studies on the organization and development of scorpions. J. Cell Sci., 68, 615-640 (1924) 〈http://jcs.biologists.org/ content/joces/s2-68/272/615.full.pdf> Sep. 2016

18) Pavlovsky EN. Studies on the organization and development of scorpions. 5. The Lungs. J. Cell Sci., 70, 135-146 (1926) 〈http://jcs. biologists.org/content/joces/s2-70/277/135.full.pdf> Sep. 2016

19) Pavlovsky EN, Zarin EJ. On the structure and ferments of the digestive organs of scorpions, J. Cell Sci., 70, 221-261 (1926) 〈http://jcs. biologists.org/content/joces/s2-70/278/221.full.pdf> Sep. 2016

20) Takashima H. Nihon-san zenkatumoku oyobi kyakushumoku. Acta Arachnologia, 8, 5-30 (1943).

21) Takashima H. Kyokuto-sasori. Acta Arachnologia, 9, 51-53 (1944).

22) Takashima H. Scorpions of Shansi, North China. Acta Arachnolo- gia, 10, 112-116 (1948)

23) Isshiki O, Yonezawa A. A scorpion (Buthus martensii Karsch) found in Japan. Med. Entomol. Zool., 11, 117-123 (1960), Eisei Doubutu.

24) Microscopical Identification of Powdered Crude Drugs (Xu G-J. ed.), The People's Health Publication House, People's Republic of China, pp. 748-749 (1986).

25) Zhang GJ, Tanaka T, Zhang LH, Ohba K. Pharmacognostical studies on the Chinese crude drug "Quanxie." Nat. Med., 48, 191-197 (1994).

26) Zhang GJ, Tanaka T, Xue-Qin L, Jie L, Xiu-Lian L, Kawamura T. Pharmacognostical studies on the Chinese crude drug "Quanxie." Nat. Med., 48, 198-202 (1994)

27) Uchida T. Systematic Zoology Vol. 7., Nakayama-Shoten Co., Ltd., Japan (1966). ISBN: 9784521071152.

28) New Illustrated Encyclopedia of the Fauna of Japan. (Okada K, Uchida K, Uchida T eds.) Hokuryukan, Japan, pp. 339-341 (1988) ISBN: 9784832600218.

29) Clarke KU. The Biology of the Arthropoda, Baifukan Co., Ltd., Japan (1979). ISBN: 9784563037628.

30) Hjelle JT. Anatomy and morphology. The Biology of Scorpions (Polis GA. ed.) Stanford University Press, U.S.A., pp. 9-63 (1990). ISBN: 0804712492.

31) Pavan M. Presence and distribution of a fluorescent substance in scorpion tegument. Boll. Soc. Ital. Biol. Sper., 30, 801-803 (1954).

32) Pavan M. Preliminary data on characteristics of fluorescent substance of the tegument in scorpions. Boll. Soc. Ital. Biol. Sper., 30, 803-805 (1954)

33) Pavan M, Vachon M. Existence of a fluorescent substance in the skin of scorpions (Arachnida). C. R. Hebd. Seances Acad. Sci., 239, 1700-1702 (1954).

34) Lawrence RF. Fluorescence in Arthropoda. J. Ent. Soc. S. Africa, 17, 167-170 (1954)

35) Stachel SJ, Stockwell SA, Vranken DLV. The fluorescence of scorpions and cataractogenesis. Chem. Biol., 6, 531-539 (1999).

36) Frost LM, Butler DR. XO'Dell B, Fet V. A coumarin as a fluorescent compound in scorpion cuticle. Scorpions 2001: In Memoriam, Gary A. Polis (Fet V, Selden PA eds.) British Arachnological Society, U.K., pp. 365-368 (2001).

37) Filshie BK, Hadley NF. Fine structure of the cuticle of the desert scorpion, Hadrurus arizonensis. Tissue Cell, 11, 249-262 (1979).

38) Krishnan G. On the cuticle of the scorpion Palamneus swammerdami. J. Cell Sci., 3, 11-22 (1953).

39) Herraiz T. Relative exposure to $\beta$-carbolines norharman and harman from foods and tobacco smoke. Food Addit. Contam., 21, 1041-1050 (2004).

40) $\overline{\text { Pfau W }}$, Skog K. Exposure to $\beta$-carbolines norharman and harman. J. Chromatogr. B Analyt. Technol. Biomed. Life Sci., 802, 115-126 (2004).

41) Nakamura Y, Fujita K, Sugiyama J, Tsuta M, Shibata M, Yoshimura M, Kokawa M, Nabetani H, Araki T. Discrimination of the geographic origin of mangoes using fluorescence fingerprint. J. Jpn. Soc. Food Sci. Tech., 59, 387-393 (2012).

42) Sugiyama J, Tsuta M. Discrimination and quantification technology for food using fluorescence fingerprint. J. Jpn. Soc. Food Sci. Tech. 60, 457-465 (2013)

43) Nguyền CY. Medicinal Plants and Traditional Medicines in Vietnam (Cẩm nang Cây thuốc và vị thuốc phương Đông và các bài thuốc ưng dụng), Nhà xuất bản Tổng hợp Tp. Hồ Chí Minh, Vietnam (2006). ISBN: 184906348

44) Konoshima M. Laboratory Manual of Botanical Morphology. Microscopic Experiments. Hirokawa Publishing Co., Japan, pp. 280-281 (2005). ISBN: 4-567-44425-6.

45) Ono H. Scorpions. Diversity and Evolution of Arthropoda (Ishikawa R ed.) Shokabo Co., Ltd., Japan, pp. 123-126, 151-153 (2008). ISBN: 9784785358297. 
46) Uchida T. Fundamental Animal Taxonomy and Phylogeny. Hokuryukan \& New Science Co., Ltd., pp. 164-165 (1988). ISBN: 4-8326-0068-0.

47) Biology of Insects, 2nd Ed. (Matsuka M, Ohno M, Kitano H eds.) Tamagawa University Press, Japan (1984). ISBN: 9784472075421.

48) Systematics of the Scorpion Family Vaejyovidae, Glossary. American Museum of Natural History, West Texas A \& M University, California Academy of Sciences, U.S.A. 〈http://www.vaejovidae. com/Glossary.htm>. Sep. 2017
49) Systematics of the Scorpion Family Vaejyovidae, Interactive Tutorial on Scorpion Anatomy. American Museum of Natural History, West Texas A \& M University, California Academy of Sciences, U.S.A. 〈http://www.vaejovidae.com/Anatomy.htm». Sep. 2017

50) Sugawara T. Mechanoreceptors of arthropods. Comp. Physiol. Biochem, 15, 97-113 (1988).

51) Kloock CT. A comparison of fluorescence in two sympatric scorpion species. J. Photochem. Photobiol. B, 91, 132-136 (2008). 